\title{
Particulate absorption of solar radiation: anthropogenic aerosols vs. dust
}

\author{
C. Wang ${ }^{1}$, G. R. Jeong ${ }^{1}$, and N. Mahowald ${ }^{2}$ \\ ${ }^{1}$ Massachusetts Institute of Technology, Cambridge, MA 02139, USA \\ ${ }^{2}$ Cornell University, Ithaca, NY 14853, USA
}

Received: 9 February 2009 - Published in Atmos. Chem. Phys. Discuss.: 10 March 2009

Revised: 8 May 2009 - Accepted: 3 June 2009 - Published: 17 June 2009

\begin{abstract}
Particulate solar absorption is a critical factor in determining the value and even sign of the direct radiative forcing of aerosols. The heating to the atmosphere and cooling to the Earth's surface caused by this absorption are hypothesized to have significant climate impacts. We find that anthropogenic aerosols play an important role around the globe in total particulate absorption of solar radiation. The global-average anthropogenic fraction in total aerosol absorbing optical depth exceeds $65 \%$ in all seasons. Combining the potentially highest dust absorption with the lowest anthropogenic absorption within our model range, this fraction would still exceed $47 \%$ in most seasons except for boreal spring (36\%) when dust abundance reaches its peak. Nevertheless, dust aerosol is still a critical absorbing constituent over places including North Africa, the entire tropical Atlantic, and during boreal spring in most part of Eurasian continent. The equality in absorbing solar radiation of dust and anthropogenic aerosols appears to be particularly important over Indian subcontinent and nearby regions as well as North Africa.
\end{abstract}

\section{Introduction}

Light-absorbing aerosols heat the atmosphere while cooling the Earth's surface. They contribute a positive component to the total direct radiative forcing (DRF) of all aerosols at the top of the atmosphere (TOA). The forcing feature along with its dynamic and thermodynamic effects of absorbing aerosols is thus different than that of scattering aerosols such as sulfate. Benefited from increasing surface measurements and satellite retrievals in recent years, the estimation of total aerosol extinction of solar radiation through both scattering

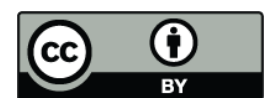

Correspondence to: C. Wang

(wangc@mit.edu) and absorption, measured by aerosol optical depth (AOD; Seinfeld and Pandis, 1998), has been greatly improved. However, without a good estimation of the absorbing fraction of this extinction, the quantity and even the sign in some cases of aerosol DRF, a critical factor in climate research (e.g. Andreae et al., 2005), will be still difficult to define.

Mineral dust and carbonaceous particles (especially the dark ones, or black carbon, BC) are two major particulate absorbing constituents. Tegen et al. (1997) estimated that dust contributes about $21-48 \%$ and black carbon contributes about $3-5 \%$ to the global total aerosol AOD. The absorbing strength (e.g. specific absorption coefficient) of dust is much lower than that of BC. However, the high atmospheric abundance of dust in particular over specific regions could still cause a considerable absorption of sunlight. The warming to the atmosphere caused by particulate absorption could affect local cloud formation and precipitation (e.g. Ackerman et al., 2000; Koren et al., 2004, 2008). Persistent existence of such a local warming could further influence atmospheric circulations on large scales, leading to a climate impact beyond the region where the actual warming occurs. It has been suggested that the solar absorption by $\mathrm{BC}$ could significantly alter the distribution of precipitation over the tropical Intertropical Convergence Zone (ITCZ), ranging from the Pacific, Atlantic, to Indian Oceans as well as the Indian summer monsoon regions (e.g. Chung and Ramanathan, 2003; Wang, 2004, 2007; Robert and Jones, 2004; Chung and Seinfeld, 2005; Lau and Kim, 2006; Ramanathan et al., 2007; Meehl et al., 2008). Previous studies have also hypothesized that the heating to the atmosphere by dust could affect the atmospheric circulation and precipitation in particular over Sahel and tropical Atlantic Ocean (e.g. Prospero and Lamb, 2003; Dunion et al., 2004; Lau et al., 2006; Yoshioka et al., 2007). Modeling studies have indicated that the climate sensitivity to radiative forcing of absorbing aerosols is different than that of relatively well-mixed greenhouse gases (e.g. Wang, 2004; Robert and Jones, 2004; Feichter et al., 2004; Chung

Published by Copernicus Publications on behalf of the European Geosciences Union. 
and Seinfeld, 2005; Hansen et al., 2005; Lau et al., 2008). Despite the rapidly growing number of studies in recent years on the climatic effects of absorbing aerosols, the interesting issue of the relative importance of dust and anthropogenic aerosols in the total particulate absorption of solar radiation has rarely been addressed.

In this paper, we report a study based on the aerosolclimate models that analyzes the solar absorptions of carbonaceous aerosols, with or without mixing with sulfate, and dust particles in different seasons. We then examine the relative importance of each of these two types of aerosols in the total particulate solar absorption over the globe and also in several different geographic locations.

\section{Methods}

We use aerosol absorbing optical depth (AAOD thereafter) to represent the solar absorption potential of aerosols. For a given atmospheric layer with a path of $\Delta z$, it can be derived as:

$$
\operatorname{AAOD}(\lambda)=\int_{z-\Delta z / 2}^{z+\Delta z / 2} \int_{0}^{D_{p}^{\max }} E_{\mathrm{abs}}\left(\lambda, D_{p}, m\right) n_{m}\left(D_{p}, z\right) d D_{p} d z
$$

Here $\lambda$ is wavelength, $E_{\mathrm{abs}}$ is the mass absorption extinction coefficient, $n_{m}$ is aerosol mass distribution function, and $D_{p}$ is aerosol size (Seinfeld and Pandis, 1998). It can be derived for a given layer or the entire atmospheric column. Note that traditionally the term of "thickness" is used for the former case and "depth" for the latter case. Here we use "depth" throughout the text for convenience. When $E_{\text {abs }}$ is replaced with mass extinction coefficient $E_{\text {ext }}$, Eq. (1) derives AOD. To save the length of the paper, the AOD and AAOD values of the $550 \mathrm{~nm}$ waveband, a typical band to represent the visible range in literature, are presented unless otherwise indicated. It can be seen that AAOD is a quantity describing the total aerosol extinction through absorption, depending solely on the properties of aerosols. Therefore, it can be used to conveniently compare the absorbing capacities of different aerosols, because for the same incoming solar radiation reaching the aerosols and local meteorological conditions, AAOD determines the heating rate due to particulate solar absorption. Note that dust absorption of thermal radiation could be a non-negligible factor in determining the climate impact of dust despite high uncertainty (e.g. Tegen et al., 1996). This effect is excluded in our current analyses.

In this study, we have used climatological AOD and AAOD distributions derived from multi-year average using numerical models driven by prescribed sea surface temperature (SST) and emissions without interannual variation. The AOD and AAOD of anthropogenic aerosols used in this study is derived based on the results of an aerosol-climate model (Kim et al., 2008) developed from the Community Atmospheric Model version 3 (CAM3), a component of the Com- munity Climate System Model (CCSM) of National Center of Atmospheric Research (NCAR) (Collins et al., 2006). The model includes seven anthropogenic aerosol types (modes), separated by size, chemical composition, and mixing state; namely 3 external sulfate (nucleation, Aitken, and accumulation), one each of external $\mathrm{BC}$ and organic carbon (OC), one internal mixture with $\mathrm{BC}$ as the core and sulfate as the shell (MBS), and one internal mixture of OC and sulfate (MOS). Each of these modes has a prognostic size distribution. The model calculates aerosol microphysical, chemical, and radiative processes based on the size, chemical composition, and also mixing state of these particles. The model results have been compared with satellite, surface, and aircraft measurements. A good agreement between modeled and observed data is seen in most of these comparisons except for events clearly under influences of episodic heavy pollution plumes in subgrid scale that could not be well represented by the model (Kim et al., 2008). The AOD and AAOD of anthropogenic aerosols at each model grid are calculated by combining contributions from all the aerosol modes. Among these modes, sulfate modes dominate the AOD while external BC and MBS mixture dominate the AAOD. External OC and MOS mixture contribute a smaller fraction in AAOD. There are, however, particularly in the AOD calculation, rather small contributions from natural sources such as DMS in sulfate production and secondary particulate organic carbon in OC that have not been separated from anthropogenic fraction owing to the complexity of such a procedure. The calculation is done based on 3-year means of modeled results. The new addition to the work of Kim et al. (2008) is the adoption of a monthly-varied biofuel emission of $\mathrm{BC}$ and $\mathrm{OC}$. The $\mathrm{BC}$ biofuel inventory is from the monthly $\mathrm{BC}$ biomass burning data of the Global Emission Inventory Activity (GEIA) (http://www.geiacenter.org). The OC biofuel emission was derived by scaling the biofuel BC emission by a factor of 6 (Bond et al., 2004). The annual $\mathrm{BC}$ and $\mathrm{OC}$ emissions are $6.1 \mathrm{Tg} / \mathrm{yr}$ and $36.9 \mathrm{Tg} / \mathrm{yr}$ for the biofuel emissions, and $8.6 \mathrm{Tg} / \mathrm{yr}$ and $20.8 \mathrm{Tg} / \mathrm{yr}$ for the fossil fuel emission, respectively.

The AOD and AAOD of mineral aerosols (dust aerosols) are derived based on the model climatology from the Model of Atmospheric Transport and Chemistry (MATCH) driven by the National Center for Environmental Prediction/National Center for Atmospheric Research (NCEP/NCAR) reanalysis data (Mahowald et al., 1997; Kistler et al., 2001) with the Dust Entrainment and Deposition Model. (Zender et al., 2003), as described in more detail in Luo et al. (2003). The model explicitly predicts dust properties in four size bins. The model results have been extensively compared to the observations from daily to annual time scale (Luo et al., 2003; Mahowald et al., 2003; Hand et al., 2004; Luo et al., 2004; Mahowald et al., 2009). These comparisons suggest that the model does a good job in capturing the annual mean and seasonal cycle of dust across a wide range of locations, but that the fine 

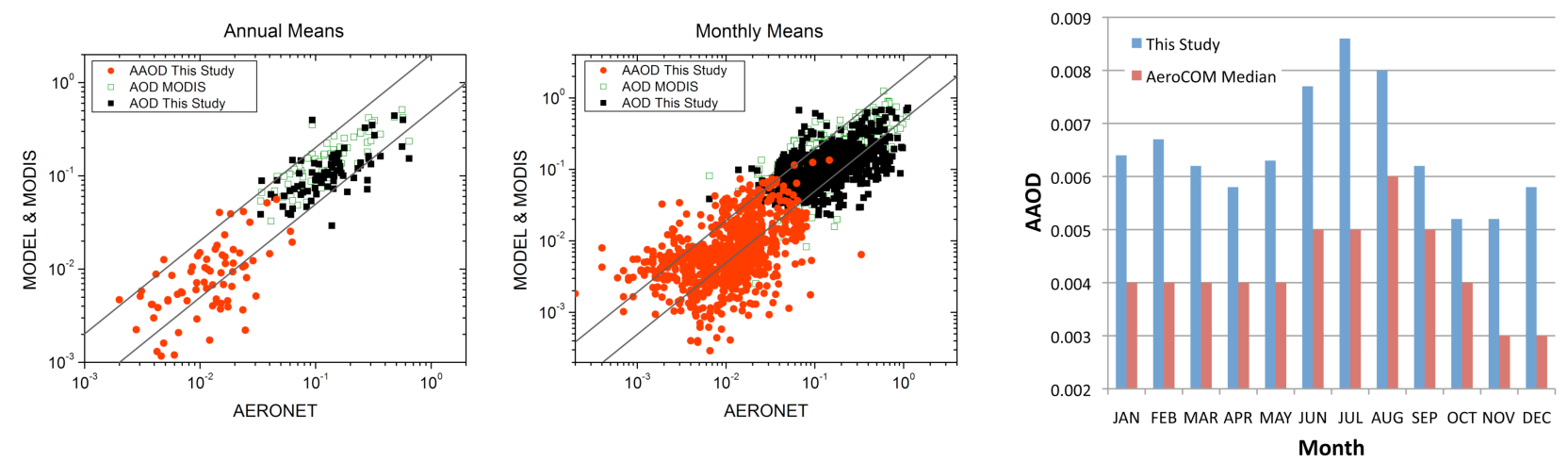

Fig. 1. Comparison of modeled AOD and AAOD from our models and AOD derived from the Moderate Resolution Imaging Spectroradiometer (MODIS) satellite data with surface measurements in 74 selected AERONET stations as: annual means (left Panel) and monthly means (middle panel). Solid lines in the figures indicate the factor-of-two boundaries. AERONET data are 5-year means over 1999-2003. Selected 74 stations all contains at least 9 months of continual measurements. MODIS AOD are 5-year means over 2000-2004. The data from our models are 3-year means. The roots of mean square error (RMSE) in monthly mean comparison ( $12 \times 74$ samples) are: AOD MODIS=0.114; AOD of this study=0.139; AAOD of this study=0.0191. The RMSE in annually mean comparison (74 samples) are: AOD MODIS=0.082; AOD of this study=0.105; AAOD of this study=0.0116. Also shown in the right panel is the comparison of our modeled monthly global mean AAOD with the median monthly-global mean AAOD by AeroCOM models (from Kinne et al., 2006; Fig. A6).

fraction is overestimated (e.g. Hand et al., 2004). We revised the size distribution following new data here, because of the importance of the dust aerosol size on optical properties to make the data more consistent with available observations (e.g. Reid et al., 2003; Grini et al., 2004; Hand et al., 2004; Mahowald et al., 2004, 2006a). We use here the same size distributions as in Mahowald et al. (2006a) for the 4 size bins, which were a result of a correction based on the new data done without rerunning the simulation, assuming the transport of dust to be linear. The indices of refraction have been derived from Patterson (1981) for the visible wavelengths, Sokolik et al. (1993) for the near infrared, and Volz (1973) for the infrared. The imaginary part of indices of refraction in the visible wavelength were scaled to match the new estimates of Sinyuk et al. (2003) and Dubovik et al. (2002) for the region from 0.33 to $0.67 \mu \mathrm{m}$. These estimates are based on satellite and surface-based field observations which actually results in less absorbing dust aerosols, and may still be susceptible to biases due to measurement errors and contaminations.

In calculating the total AOD data, we have also used climatological output (10-year mean) of CAM3 sea salt model for the current climate (Mahowald et al., 2006b). The model includes 4 size bins $(0.2-1.0,1.0-3.0,3.0-10.0,10.0-20.0 \mu \mathrm{m}$ diameter). A source parameterization developed by Gong et al. (1997) with a correction for humidity biases following Andreas (1998) was adopted. The mass going into each size bin is wind speed and relative humidity independent, and is $2 \%, 21 \%, 49 \%$ and $28 \%$ of the total source, for size bins $1-4$, respectively. The loss mechanisms for sea-salt aerosols include gravitational settling, turbulent dry deposition and wet deposition and are parameterized within the model, includ- ing the effects of hygroscopic growth on gravitational settling rates (Seinfeld and Pandis, 1998; Rasch et al., 2001). Optical depths are calculated using a humidity dependence in the optical parameters (Hess et al., 1998; Collins et al., 2002). The output was originally gridded at $\mathrm{T} 42$ resolution ( 2.8 by 2.8 degree horizontally) and remapped into CAM3 grids before AOD was calculated. Due to limited contribution of sea salt to the total AAOD, we did not include it in such calculations.

The calculated total AOD and AAOD combining both anthropogenic and dust aerosols have been compared with AOD measurements and AAOD retrievals made in 74 stations of the Aerosol Robotic Network (AERONET; http: //aeronet.gsfc.nasa.gov/; inversion product level 2.0 version 2.0, March 2008; Holben et al., 1998) across the globe, overlapped with AOD derived from the Moderate Resolution Imaging Spectroradiometer (MODIS; http://modis.gsfc. nasa.gov/; level 3, monthly means; Remer et al., 2005) satellite data in a 5-year period over 2000-2004. The criterion of selecting these stations from total AERONET inventory is that each of them has at least 9 months of continued measurements during 1999-2003; monthly means during this period are then derived based on the raw data. The multi-year monthly mean data of both AERONET and MODIS are averaged over the 5-year period to derive their climatological monthly means and annual means. Then, the modeled and MODIS data are mapped into the locations of AERONET stations using the closest grid or the average over multiple such grids. Clear correlation and reasonably good agreement between our results and AERONET and MODIS data are found (Fig. 1, the left and middle panels). When compared with the median AAOD of AeroCOM models (Kinne 

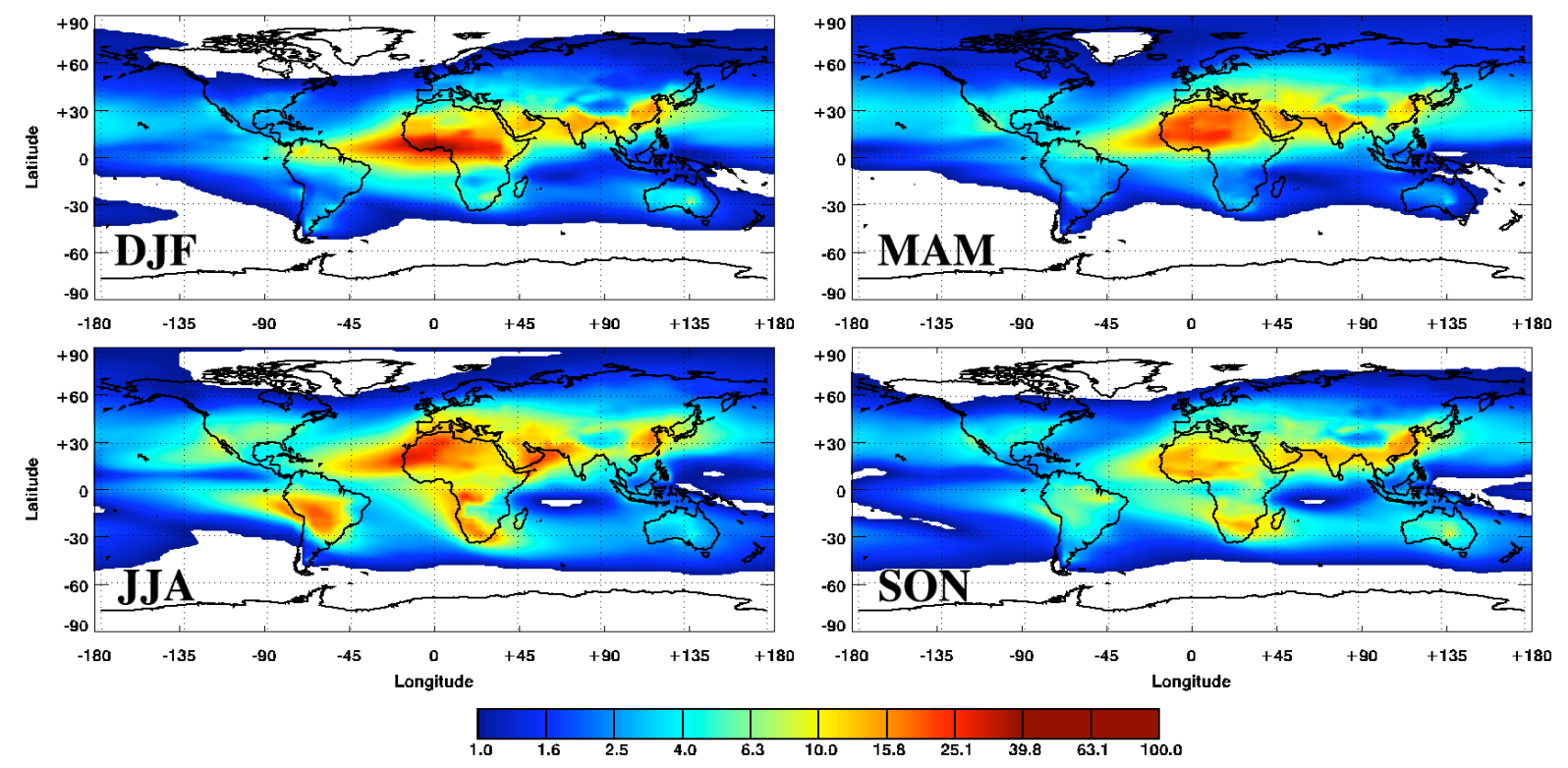

Fig. 2. Horizontal distribution of column aerosol absorbing optical depth (anthropogenic + dust; AAOD) in $10^{-3}$ averaged in four seasons.

et al., 2006), the monthly and global mean AAOD calculated from our models are about 55\% higher in average (ranging from $\sim 20$ to $90 \%$; Fig. 1, the right panel), owing clearly to the differences between our model and AeroCOM models in $\mathrm{BC}$ emissions (14.7 TgC in our model vs. 7.1 TgC in AeroCOM; see Dentener et al., 2006) and aerosol physiochemical processes (the majority of AeroCOM models used single moment aerosol scheme and excluded core-shell mixture of BC and sulfate). The modeled spatial distributions of monthly mean AAOD by our model are largely similar to those represent the median predictions of all AeroCOM models (not shown). Many detailed model-observation comparison results can be found in Kim et al. (2008).

In order to provide a comparison for our AOD calculation, we have used the AOD data of carbonceous, sulfate, mineral dust, and sea salt from the Goddard Chemistry Aerosol Radiation and Transport (GOCART; Chin et al., 2000), based on 5-year means over the period of 2000-2004. GOCART model is an atmospheric transport model of multi-component of aerosols based on a single moment (mass only) scheme. Its results have been extensively compared with surface and satellite data (e.g. Chin, M., et al., 2002).

\section{Results}

When combining contributions from dust and anthropogenic aerosols, the highest AAOD values in all seasons appear over North Africa, spatially extending into the tropical Atlantic Oceans. Other high centers throughout all seasons are over the Arabian Sea to the Indian subcontinent and the east coast of China. Seasonal high centers of AAOD with value equal to or higher than $10^{-2}$ include Amazonia (in June to August or JJA), South Africa (JJA and September to November or SON), Australia (SON), and North America (JJA) (Fig. 2). In addition, there are also several belts with relatively high AAOD spreading from land to open waters particularly in the tropics and subtropical regions. Note that even in these high AAOD centers throughout all year long, the actual AAOD values there still vary significantly with seasons.

Some of the above-indicated high centers of AAOD are known to be associated with dust sources. However, these regions are often under the influence of anthropogenic aerosols as well. In order to examine the relative importance of dust and anthropogenic aerosols in solar absorption, we have derived the distributions of fractional contribution of anthropogenic AAOD in the total AAOD during various seasons (Fig. 3, the upper panels). The area-weighted global and seasonal mean value of this fraction is 0.72 (DJF), 0.65 (MAM), $0.80(\mathrm{JJA})$, and $0.75(\mathrm{SON})$, respectively, with an annual mean of 0.73 . This suggests that the anthropogenic aerosols dominate the AAOD in most of the regions. In comparison, dust contribution to AOD is much more significant. When combining dust and anthropogenic AOD, the anthropogenic fraction is much smaller over the dust-influenced areas, and the coverage of these low anthropogenic fraction regions is also larger comparing to the case of AAOD (Fig. 3, the lower panels). However, outside the dust-influenced regions, anthropogenic fraction in AOD has nearly the same dominance as in AAOD. Note an artifact over the remote oceans where the anthropogenic fraction is high due to sulfate aerosols largely from DMS oxidation that should be separated from anthropogenic fraction. When weighing in 

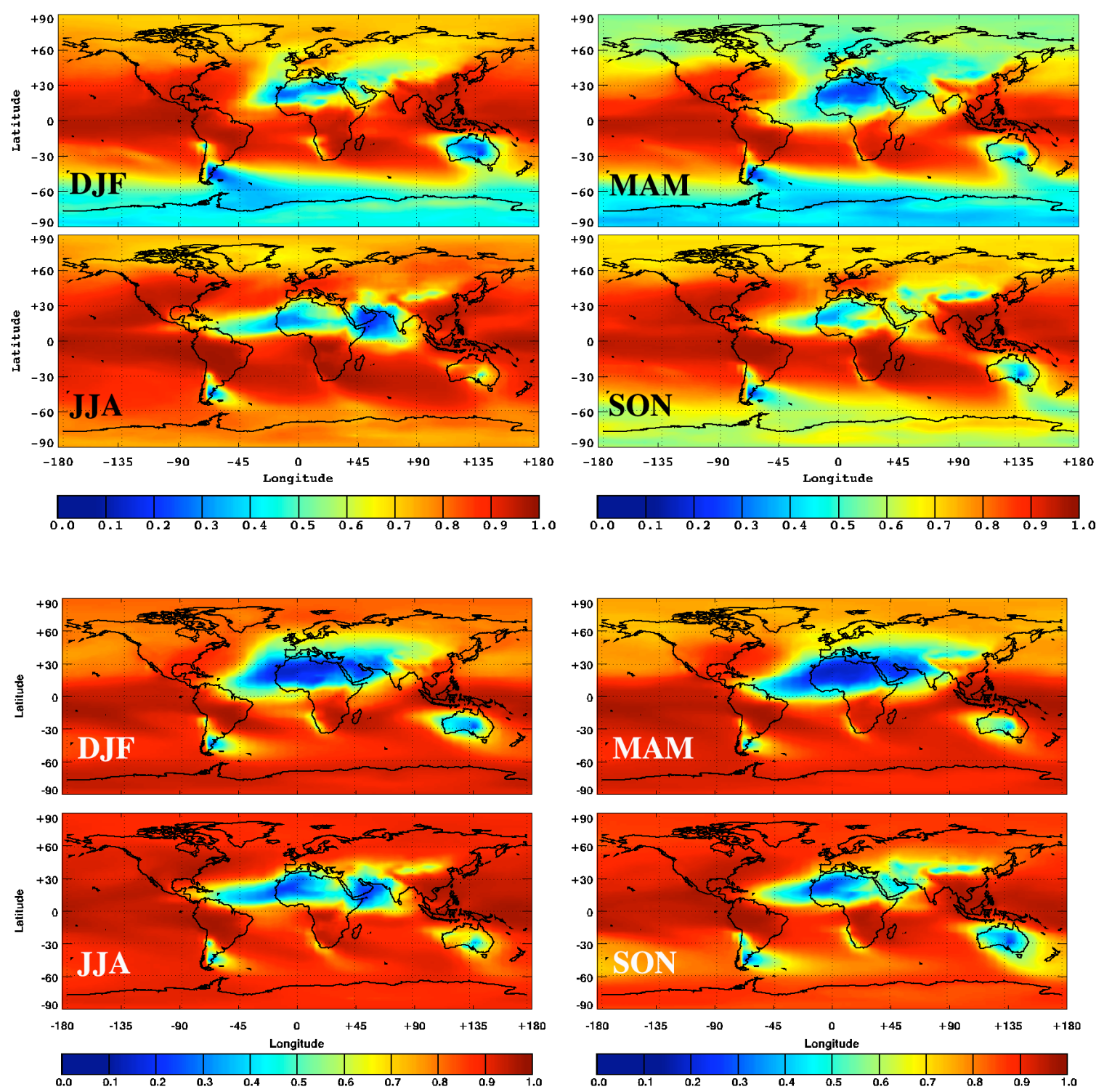

Fig. 3. (Upper panels): Fraction of aerosol absorbing optical depth (AAOD) of anthropogenic aerosols in the total AAOD in four seasons. (Lower panels): Fraction of aerosol optical depth (AOD) of anthropogenic aerosols in the summation of dust and anthropogenic AOD in four seasons. Data are from the baseline estimation.

the sea salt aerosols, the global mean anthropogenic, dust, and sea salt fraction in total AOD calculated based on areameans of our models is $0.4,0.12$, and 0.48 , respectively, while $0.59,0.18$, and 0.23 of GOCART model (we calculated the values using area-mean method based on the original data), respectively. The corresponding values listed in Tegen et al. (1997) are 0.57, 0.35, and 0.08. All three results show the similar substantial contribution from anthropogenic aerosols to the total AOD while differing most significantly in non-absorbing sea salt contribution. Nevertheless, we hence demonstrate that the anthropogenic aerosols make the largest global contribution to both total AOD and AAOD.
We do realize that, however, uncertainties exist in modeled aerosol abundance as well as optical properties. To provide a potential range of modeling results for above estimations of anthropogenic fraction in AAOD, besides the baseline results we have also calculated a low estimation by combining the lowest anthropogenic AAOD with the highest dust AAOD, and a high estimation by combining the highest anthropogenic AAOD with the lowest dust AAOD, all based on possible configurations in our models. It has been indicated in Kim et al. (2008) that lowering carbonaceous emissions is the most effective way to reduce the anthropogenic AAOD. In addition, for the same emissions it could lead to a slightly higher AAOD by adopting a single moment (mass only) 
Table 1. Global-mean fractions of anthropogenic aerosols in the total (dust plus anthropogenic) aerosol absorbing optical depth (AAOD).

\begin{tabular}{llll}
\hline & $\begin{array}{l}\text { High } \\
\text { Estimation }\end{array}$ & $\begin{array}{l}\text { Baseline } \\
\text { Estimation }\end{array}$ & $\begin{array}{l}\text { Low } \\
\text { Estimation }\end{array}$ \\
\hline Annual & 0.82 & 0.73 & 0.47 \\
DJF & 0.82 & 0.72 & 0.47 \\
MAM & 0.77 & 0.65 & 0.36 \\
JJA & 0.86 & 0.80 & 0.56 \\
SON & 0.83 & 0.72 & 0.47 \\
\hline
\end{tabular}

aerosol model using prescribed geometric size and assuming all aerosol constituents are external mixtures. Thus, we derive our low anthropogenic AAOD distribution by using the model run driven by a lower anthropogenic carbonaceous emission (Bond et al., 2004; $8 \mathrm{Tg}$ for BC and 33.8 Tg for OC in annual emissions, or a $44 \%$ and a $38 \%$ reduction from our baseline run, respectively; see Kim et al., 2008). The high anthropogenic AAOD distribution is derived using the current baseline run result but calculating AAOD using a single-moment and external mixing procedure (Kim et al., 2008). For dust aerosols, we have used various scenarios corresponding to different size distributions and mineralogical compositions in particular the amount of hematite based on Jeong and Sokolik (2007) to derived the upper and lower bounds of optical properties regarding solar absorption for each dust bin. These two sets approximate a bulk single scattering albedo value (combing all 4 bins) of 0.68 and 0.94 (compared to 0.89 in the baseline calculation), representing respectively the maximum and minimum estimation of dust solar absorption. These two sets of parameters are then used to derive the high and low dust AAOD distributions. The high and low estimations of global-mean anthropogenic fraction in the total AAOD along with the baseline results are listed in Table 1. The low estimations are generally equal to or higher than 0.47 except for boreal spring (0.36), implying that anthropogenic aerosols account nearly half of the combined AAOD in most of the time. Note that the differences in dust emissions and lifetime (removal processes) in various models also contribute to the uncertainty in modeled dust AAOD. A recent model survey indicated that a range of factor of 4 in modeled dust burdens (usually smaller when converted to AAOD) could be resulted from such differences among models (Zender et al., 2004). However, this difference is still smaller than the 5-fold range in dust AAOD derived here by using the high and low single scattering albedo.

It is worthy indicating that dust absorption in the UV band is much stronger than in the visible band. Using $300 \mathrm{~nm}$ instead of $550 \mathrm{~nm}$ in our calculation, the global and annual mean anthropogenic fraction in AAOD would be $48 \%$ instead of $73 \%$ (not shown). However, considering the
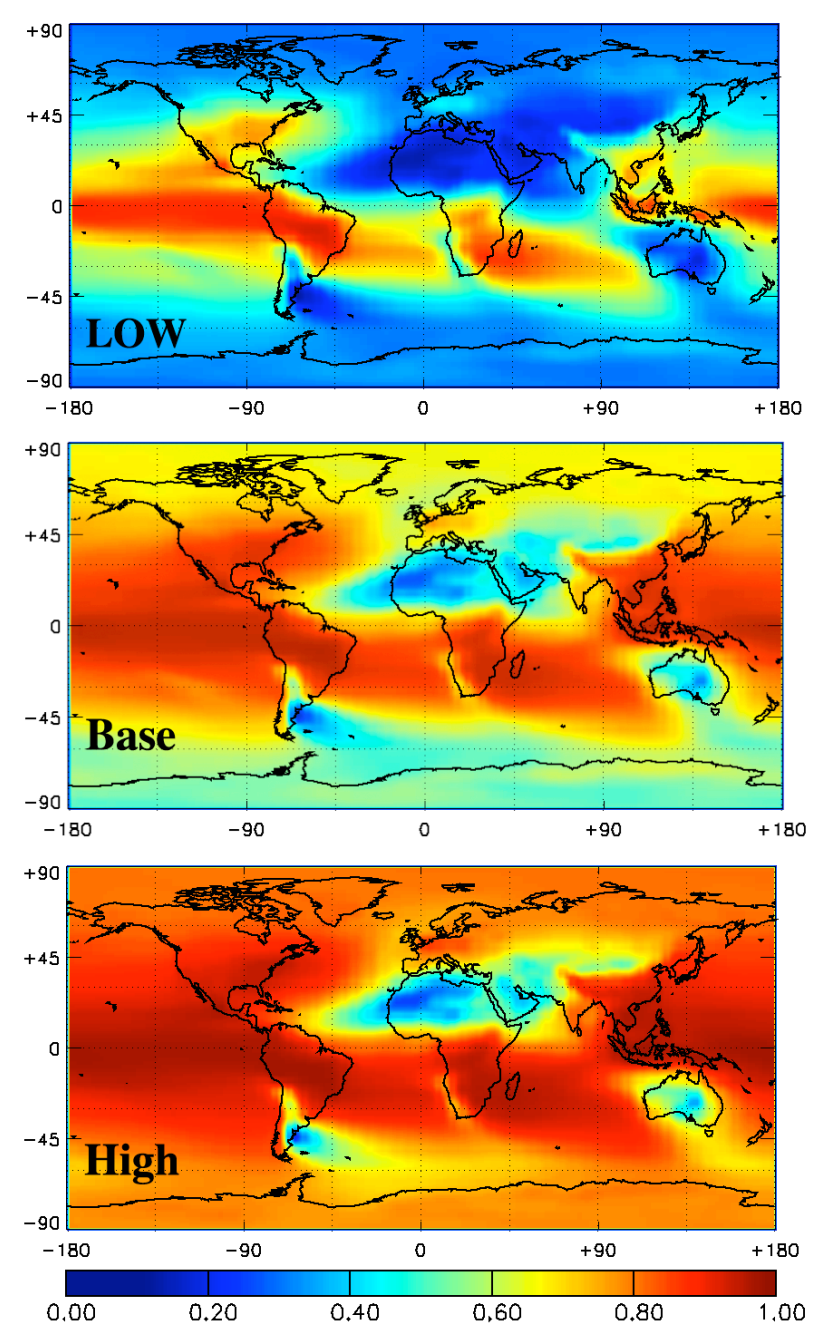

Fig. 4. Anthropogenic fraction of the total aerosol absorbing optical depth (AAOD) derived from: (upper panel) the low estimation, (middle panel) the baseline estimation, and (lower panel) the high estimation. All results shown are annual means.

dominance of solar energy in the visible comparing to UV range and also the rapid increase of dust single scattering albedo with wavelength moving from UV to the visible range (e.g. Jeong and Sokolik, 2007), our conclusion drawn based on the $550 \mathrm{~nm}$ band analyses should be still valid for the integrated particulate absorption.

Despite this dominance of anthropogenic aerosols in global-mean particulate solar absorption, dust still plays a critical role in several regions including North Africa, northern Atlantic Ocean between tropics and 30N, Arabian Sea, South America below 40S, Australia, and Arctic region. In particular in our low estimation the dust contribution to total AAOD is higher than $80 \%$ over these regions (Fig. 4). The annual mean distribution show that anthropogenic fraction outside of the major dust-influenced regions are about the same in all three cases, significantly higher than 0.8 (Fig. 4). 

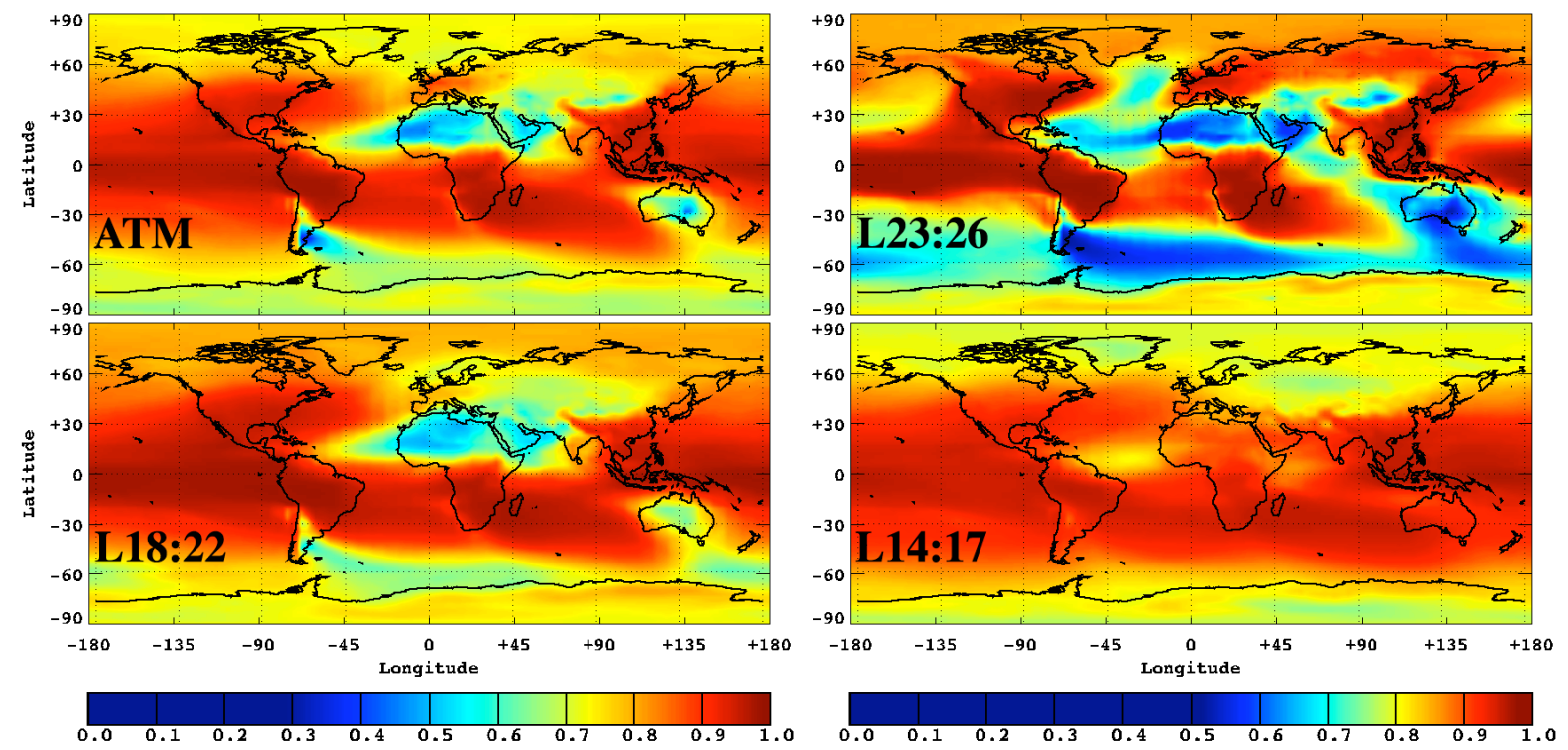

Fig. 5. Fraction of aerosol absorbing optical depth (AAOD) of anthropogenic aerosols in the total AAOD as annual means through the entire model atmospheric column (ATM) as well as within three vertical layers ranging from the planetary boundary layer (Layer 23 and 26), middle troposphere (Layer 18 to 22), to the upper troposphere (Layer 14 to 17). Data are from the baseline estimation.

During the boreal spring, the contribution of dust in solar absorption over most of the Eurasia in our baseline estimation is comparable to (actually higher in the low estimation) that of anthropogenic aerosols. Nevertheless it becomes less important in the rest of the seasons. Note that the absolute value of total AAOD over Eurasia does not change significantly from boreal spring to fall (Fig. 2). It is the increase of anthropogenic AAOD occurring in the boreal summer and fall that fills in the deficit left by decreasing dust AAOD. Interestingly, anthropogenic fraction of total AAOD over the Polar Regions change from below 0.4 in low estimation, to about 0.5 in the base estimation, and then to above 0.6 in our high estimation (Fig. 4), reflecting a relatively high abundance of dust than black carbon in these places.

We also find that dust contributes more substantially to the total AAOD in the lowermost troposphere than in the rest of the atmosphere (Fig. 5). In opposite, anthropogenic aerosols dominate AAOD in the upper troposphere. In the middle free troposphere, the contribution of dust to total AAOD in our baseline results merely exceeds $50 \%$ over any place even the dust source regions. Interestingly, our baseline estimation shows that anthropogenic aerosols dominate the aerosol solar absorption over east coast of China throughout all seasons, even including the boreal spring when dust abundance peaks there.

Wang (2007) suggests that the BC absorption in eastern most Pacific and western Pacific tropics might exert a forcing to the lower atmosphere, affect the strength of the Walker circulation, and thus cause a redistribution of convective precipitation over the entire Pacific, a mechanism much similar to that of ENSO events. Our results demonstrate that over the above-mentioned two regions, anthropogenic aerosol contributes constantly over $90 \%$ in total particulate solar absorption (Figs. 3 and 4), supporting the case of the hypothetic role of $\mathrm{BC}$ in causing redistribution of precipitation in the Pacific ITCZ.

The roles of absorbing anthropogenic aerosols on Indian summer monsoon circulation have been recently hypothesized (e.g. Ramanathan et al., 2005; Lau et al., 2006; Kim et al., 2006; Wang, 2007; Meehl et al., 2007; Lau et al., 2008). It has been also suggested that Sahel dust could influence circulation and precipitation in tropical Atlantic ITCZ and West Africa monsoon region (e.g. Prospero and Lamb, 2003; Dunion et al., 2004; Yoshioka et al., 2007). We find that the fractional contribution of anthropogenic aerosols to the total AAOD varies in seasons over the Indian subcontinent and surrounding regions. Dust (mainly from Mideast deserts) and anthropogenic aerosol each plays a different role in different seasons over this region. From boreal fall to winter, anthropogenic aerosols dominate the particulate absorption over both the Arabian Sea and the subcontinent (Fig. 3). Dust mainly occupies the lowermost troposphere away from the subcontinent while absorbing anthropogenic aerosol stays over the land and well extends vertically into the free troposphere (Fig. 6). However, during the premonsoon and monsoon season (MAM and JJA), the high dust AAOD zone penetrates into the land area and makes a contribution quantitatively comparable to that of anthropogenic aerosols in the total AAOD (Fig. 6). Note that in the boreal spring, distributions of dust and anthropogenic 


\section{(a)}
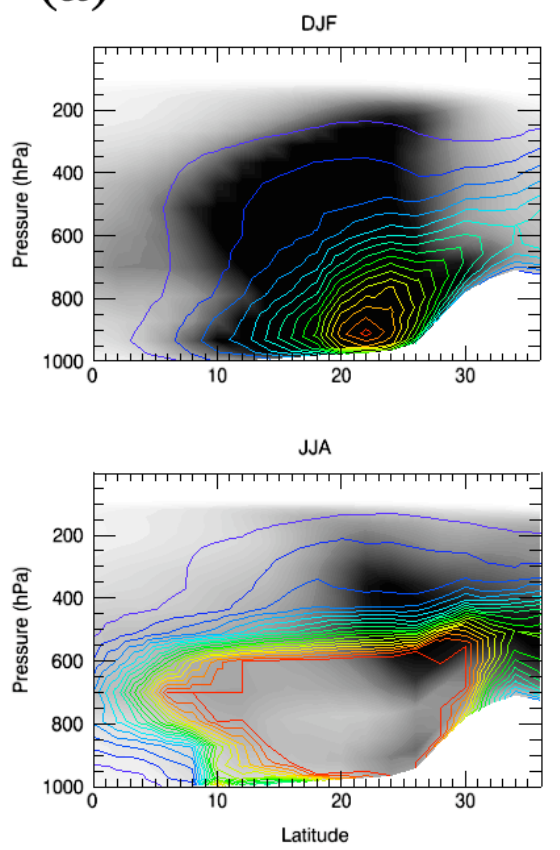

(b)
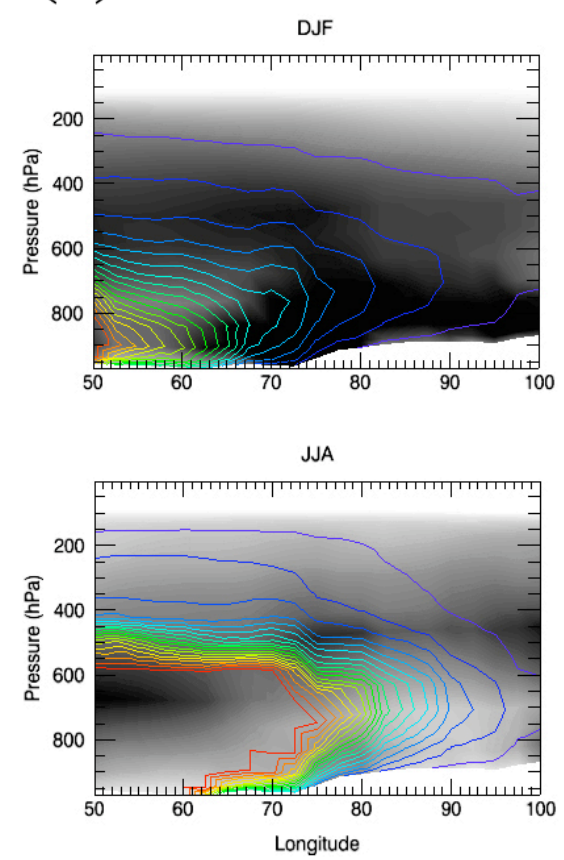
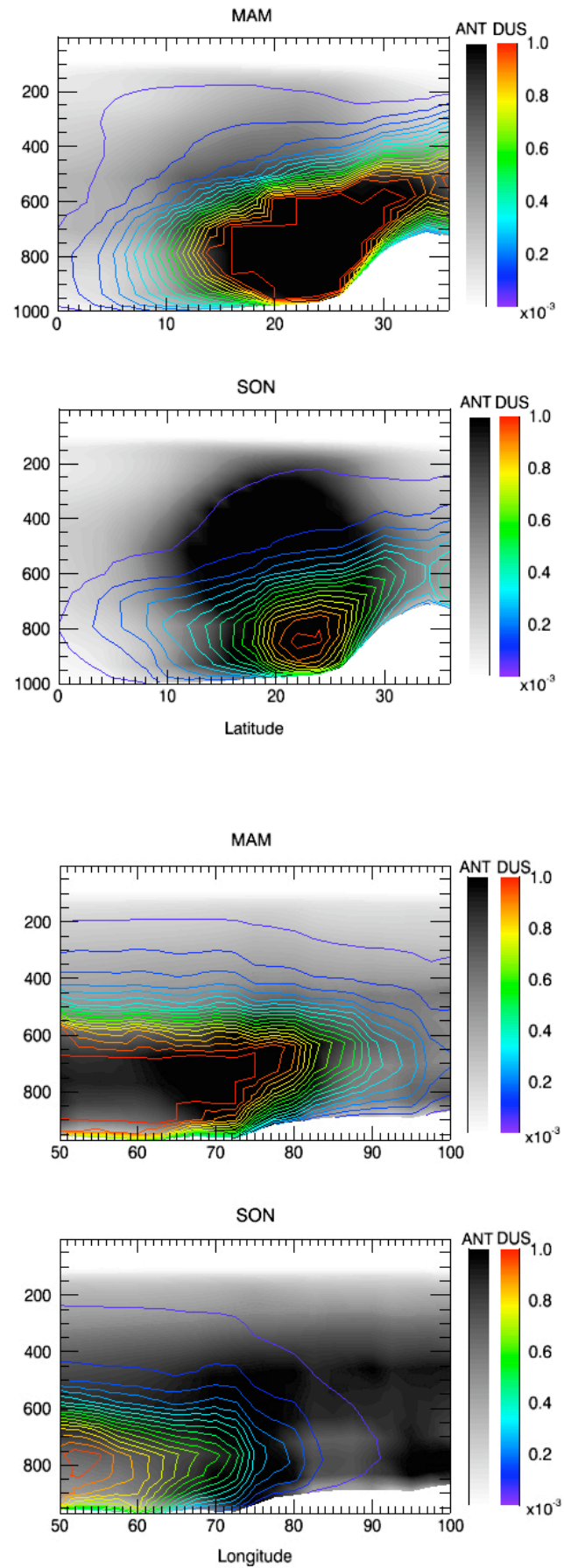

Fig. 6. Aerosol absorbing optical depth of anthropogenic and dust aerosols in different seasons over the Indian summer monsoon region. Data are: (a) zonally (4 upper panels), and (b) meridionally (4 lower panels), respectively, averaged within a domain bounded by 50-100 E and $0-36$ N. Data reflect the baseline estimation.

AAOD appear to overlap each other over the Indian subcontinent. Their combined absorption concentrates from surface to about $600 \mathrm{hPa}$. Due to precipitation scavenging, the abundance of absorbing anthropogenic aerosols during the summer monsoon season is reduced in the above-mentioned atmospheric layer over the land. The high centers of anthropogenic AAOD are elevated along the slope of the Tibetan Plateau. Dust AAOD in this season still distributes close to the surface, however, with evidently lower value. Our result along with other similar ones (e.g. Kim et al., 2006; Lau et 

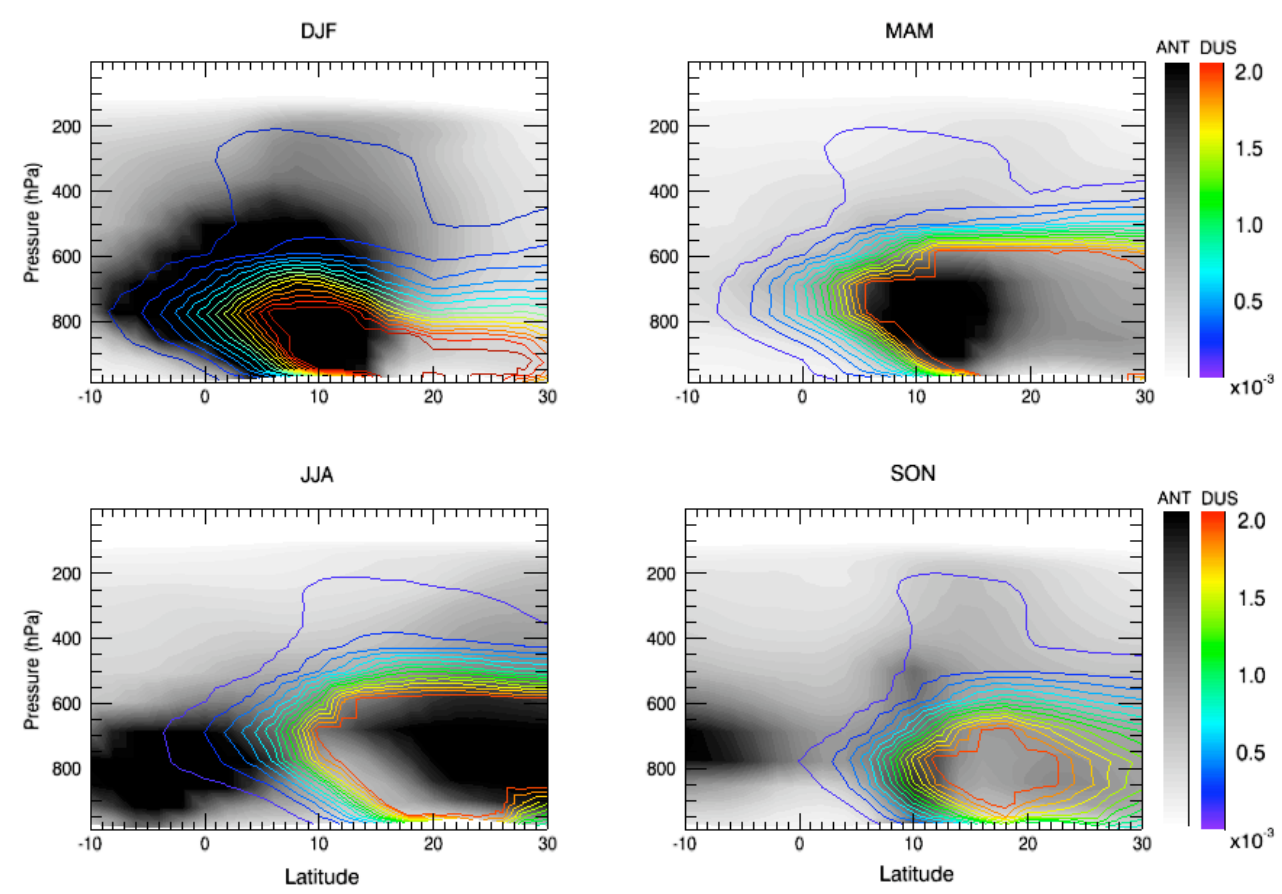

Fig. 7. Zonal distributions of aerosol absorbing optical depth in four seasons over the West African monsoon (WAM) region and surrounding areas. Data are zonally averaged within a domain of 30 W-30 E and 10 S-30 N. Data reflect the baseline estimation.

al., 2008; Gautam et al., 2009a, b) all suggest that the solar absorption by dust aerosols can not be neglected when studying the influence of particulate absorption on Indian summer monsoon circulation.

Over the North Africa and West Africa monsoon regions, clear seasonality in component AAOD distributions has been found (Fig. 7). Specifically through the months of JJA, anthropogenic AAOD distribution has two high centers due to biomass burning from different sources. Interestingly, except for the months of SON the high center of anthropogenic AAOD always overlap with that of dust AAOD through the vertical column below $600 \mathrm{hPa}$ (note that in the months of DJF anthropogenic AAOD high centers appear to extend above dust layer, similar to the recent observed feature in Haywood et al., 2008), indicating that anthropogenic aerosol can be a critical component in causing particulate absorption even inside the dust plumes. This also suggests a mixing between anthropogenic and dust aerosols to be possible within these plumes.

\section{Conclusions}

We find that anthropogenic aerosols play an important role around the globe in total particulate absorption of solar radiation. The global average anthropogenic fraction in total aerosol absorbing optical depth exceeds $65 \%$ throughout all seasons in our baseline and high estimation and accounts more than $47 \%$ except during the boreal spring in our low estimation. The contribution of anthropogenic aerosol in par- ticulate solar absorption can be found even inside heavy dust plumes out of Africa. However, dust aerosols are still a critical absorbing constituent in several places including North Africa, the entire tropical Atlantic, and during boreal spring in most part of Eurasian continent. The equality in solar absorption of dust and anthropogenic aerosols appears to be particularly critical over Indian Subcontinent and nearby regions as well as North Africa, where the summer monsoon circulation and precipitation are hypothesized to be influenced by atmospheric warming and surface cooling caused by absorbing aerosols. Absorbing aerosols exert a positive direct forcing at the top of atmosphere, in opposite to the general cooling effect of scattering aerosols over the warming caused by greenhouse gases. A good estimation of the quantity and even the sign of aerosol direct radiative forcing can be only established with a better understanding of the strength of particulate solar absorption, arguably the most uncertain property of aerosols.

Future studies will further address the issues related to the complicated mixing between dust and anthropogenic aerosol constituents and the climatic effects caused by the absorption of dust and anthropogenic aerosols as well as their mixtures. Measurements of aerosol solar absorption ranging from in-situ to satellite with reasonable vertical resolution would greatly advance the efforts. 
Acknowledgements. We thank D. Kim for assisting in model setup and processing of output data, J. V. Martins and L. Remer for providing MODIS AOD data, and M. Chin for providing GOCART modeling data. We also appreciate the AERONET principal investigators and teams, the GEIA-ACCENT principal investigators and teams for making their data available to this study. Lorraine Remer and two anonymous reviewers provided many constructive comments, leading to a significant improvement of the manuscript. The NSF (ATM-0329759), the NASA (NNX07AI49G), and the MIT Joint Program on the Science and Policy of Global Change supported this research.

Edited by: Y. Balkanski

\section{References}

Ackerman, A. S., Toon, O. B., Stevens, D. E., Heymsfield, A. J., Ramanathan, V., and Welton, E. J.: Reduction of tropical cloudiness by soot, Science, 208, 1042-1047, 2000.

Andreas, E.: A new sea spray generation function for wind speeds up to $32 \mathrm{~m} / \mathrm{s}$, J. Phys. Oceanogr., 28, 2175-2184, 1998.

Andreae, M. O., Jones, C. D., and Cox, P. M.: Strong present-day aerosol cooling implies a hot future, Nature, 435, 1187-1190, doi:10.1038/nature03671, 2005.

Bond, T. C., Streets, D. G., Yarber, K. F., Nelson, S. M., Woo, J. H., and Klimont, Z.: A technology-based global inventory of black and organic carbon emissions from combustion, J. Geophys. Res., 109, D14203, doi:10.1029/2003JD003697, 2004.

Chin, M., Rood, R. B., Lin, S. J., Muller, J. F., and Thomspon, A. M.: Atmosphericsulfur cycle in the global model GOCART: Model description and global properties, J. Geophys. Res., 105, 671-687, 2000.

Chin, M., Ginoux, P., Kinne, S., Torres, O., Holben, B. N., Duncan, B. N., Martin, R. V., Logan, J. A., Higurashi, A., and Nakajima, T.: Tropospheric aerosol optical thickness from the GOCART model and comparisons with satellite and Sun photometer measurements, J. Atmos. Sci., 59, 461-483, 2002.

Chung, S. H. and Seinfeld, J. H.: Climate response of direct radiative forcing of anthropogenic black carbon, J. Geophys. Res., 110, D11102, doi:10.1029/2004JD005441, 2005.

Collins, W., Rasch, P., Eaton, B., Fillmore, D., Kiehl, J., Beck, C., and Zender, C.: Simulation of aerosol distributions and radiative forcing for INDOEX: Regional climate impacts, J. Geophys. Res., 107, 8028, doi:10.1029/2000JD000032, 2002.

Collins, W. D., Blackmon, M., Bonan, G. B., et al.: The Community Climate System Model Version 3 (CCSM3), J. Climate, 19, 2122-2143, 2006.

Dubovik, O., Holben, B. N., Eck, T. F., Smirnov, A., Kaufman, Y. J., King, M. D., Tanré, D., and Slutsker, I.: Variability of absorption and optical properties of key aerosol types observed in worldwide locations, J. Atmos. Sci., 59, 590-608, 2002.

Dunion, J. P. and Velden, C. S.: The impact of the Saharan air layer on Atlantic tropical cyclone activity, Bull. Am. Meteorol. Soc., 85, 353-365, 2004.

Feichter, J., Roeckner, E., Lohmann, U., and Liepert, B.: Nonlinear aspects of the climate response to greenhouse gas and aerosol forcing, J. Climate, 17, 2384-2398, 2004.
Gautam, R., Liu, Z., Singh, R. P., and Hsu, N. C.: Two contrasting dust-dominant periods over India observed from MODIS and CALIPSO data, Geophys. Res. Lett., 36, L06813, doi:10.1029/2008GL036967, 2009a.

Gautam, R., Hsu, N. C., Lau, K. M., Tsay, S. C., and Kafatos, M.: Enhanced pre-monsoon warming over the Himalayan-Gangetic region from 1979 to 2007, Geophys. Res. Lett., 36, L07704, doi:10.1029/2009GL037641, 2009b.

Gong, S. L., Barrie, L. A., and Blanchet, J. P.: Modeling sea-salt aerosols in the atmosphere: 1 . Model development, J. Geophys. Res., 102, 3805-3818, 1997.

Grini, A. and Zender, C.: Roles of saltation, sandblasting, and wind speed variability on mineral dust aerosol size distribution during the Puerto Rican Dust Experiment (PRIDE), J. Geophys. Res., 109, D07202, doi:10.1029/2003JD004233, 2004.

Hand, J., Mahowald, N., Chen, Y., Siefert, R. L., Luo, C., Subramaniam, A., and Fung, I.: Estimates of soluble iron from observations and a global mineral aerosol model: Biogeochemical implications, J. Geophys. Res., 109, D17205, doi:10.1029/2004JD004574, 2004.

Hansen, J., Sato, M., Ruedy, R., et al.: Efficacy of climate forcings, J. Geophys. Res., 110, D18104, doi:10.1029/2005JD005776, 2005.

Haywood, J. M., Pelon, J., Formenti, P., et al.: Overview of the Dust and Biomass-burning Experiment and African Monsoon Multidisciplinary Analysis Special Observing Period-0, J. Geophys. Res., 113, D00C17, doi:10.1029/2008JD010077, 2008.

Hess, M., Kopke, P., and Schult, I.: Optical properties of aerosols and clouds: The software package OPAC, Bull. Am. Meteorol. Soc., 79, 831-844, 1998.

Holben B. N., Eck, T. F., Slutsker, I., Tanre, D., Buis, J. P., Setzer, A., Vermote, E., Reagan, J. A., Kaufman, Y., Nakajima, T., Lavenu, F., Jankowiak, I., and Smirnov, A.: AERONET - A federated instrument network and data archive for aerosol characterization, Rem. Sens. Environ., 66, 1-16, 1998.

Jeong, G. R. and Sokolik, I. N.: Effect of mineral dust aerosols on the photolysis rates in the clean and polluted marine environments, J. Geophys. Res., 112, D21308, doi:10.1029/2007JD008442, 2007.

Kim, D., Wang, C., Ekman, A. M. L., Barth, M. C., and Rasch, P.: Distribution and direct radiative forcing of carbonaceous and sulfate aerosols in an interactive size-resolving aerosol-climate model, J. Geophys. Res., 113, D16309, doi:10.1029/2007JD009756, 2008.

Kinne, S., Schulz, M., Textor, C., Guibert, S., Balkanski, Y., Bauer, S. E., Berntsen, T., Berglen, T. F., Boucher, O., Chin, M., Collins, W., Dentener, F., Diehl, T., Easter, R., Feichter, J., Fillmore, D., Ghan, S., Ginoux, P., Gong, S., Grini, A., Hendricks, J., Herzog, M., Horowitz, L., Isaksen, I., Iversen, T., Kirkevåg, A., Kloster, S., Koch, D., Kristjansson, J. E., Krol, M., Lauer, A., Lamarque, J. F., Lesins, G., Liu, X., Lohmann, U., Montanaro, V., Myhre, G., Penner, J., Pitari, G., Reddy, S., Seland, O., Stier, P., Takemura, T., and Tie, X.: An AeroCom initial assessment - optical properties in aerosol component modules of global models, Atmos. Chem. Phys., 6, 1815-1834, 2006,

http://www.atmos-chem-phys.net/6/1815/2006/.

Kim, M. K., Lau, W. K. M., Chin, M., Kim, K. M., Sud, Y. C., and Walker, G. K.: Atmospheric teleconnection over Eurasia induced by aerosol radiative forcing during boreal spring, J. Climate, 19, 
4700-4718, 2006.

Kistler, R., Kalnay, E., Collins, W., et al.: The NCEP-NCAR 50Year Reanalysis: Monthly Means CD-ROM and Documentation, Bull. Am. Meteorol. Soc., 82, 247-267, 2001.

Koren I., Martins, J. V., Remer, L. A., and Afargan, H.: Smoke invigoration versus inhibition of clouds over the Amazon, Science, 321, 946-949, 2008.

Koren, I., Kaufman, Y. J., Remer, L. A., and Martins, J. V.: Measurement of the effect of Amazon smoke on inhibition of cloud formation, Science, 303, 1342-1345, 2004.

Lau, K. M., Ramanathan, V., Wu, G. X., et al.: The Joint AerosolMonsoon Experiment, A new Challenge for monsoon climate research, Bull. Am. Meteorol. Soc., 89, 369-383, 2008.

Lau, K. M. and Kim, K. M.: Observational relationships between aerosol and Asian monsoon rainfall, and circulation, Geophys. Res. Lett., 33, L21810, doi:10.1029/2006GL027546, 2006.

Luo, C., Mahowald, N. M., and del Corral, J.: Sensitivity study of meteorological parameters on mineral aerosol mobilization, transport, and distribution, J. Geophys. Res., 108, 4447, doi:10.1029/2003JD003483, 2003.

Luo, C., Mahowald, N., and Jones, C.: Temporal variability of dust mobilization and concentration in source regions, J. Geophys. Res., 109, D20202, doi:10.1029/2004JD004861, 2004.

Luo, C., Mahowald, N., and del Corral, J.: Sensitivity study of meteorological parameters on mineral aerosol mobilization, transport and distribution, J. Geophys. Res., 108, 4447, doi:10.1029/2003JD0003483, 2003.

Mahowald, N., Engelstaedter, S., and Luo, C., et al.: Atmospheric iron deposition: Global distribution, variability and human perturbations, Ann. Rev. Mar. Sci., 1, 245-278, doi:10.1146/annurev/marine.010908.163727, 2009.

Mahowald, N., Luo, C., del Corral, J., and Zender, C. S.: Interannual variability in atmospheric mineral aerosols from a 22-year model simulation and observational data, J. Geophys. Res., 108, 4352, doi:10.1029/2002JD002821, 2003.

Mahowald, N., Muhs, D., Levis, S., Yoshioka, M., Zender, C. S., and Rasch, P. J.: Change in atmospheric mineral aerosols in response to climate: last glacial period, pre-industrial, modern and doubled-carbon dioxide climates, J. Geophys. Res., 111, D10202, doi:10.1029/2005JD006653, 2006a.

Mahowald, N., Lamarque, J. F., Tie, X. X., and Wolff, E.: Seasalt aerosol response to climate change: Last Glacial Maximum, preindustrial, and doubled carbon dioxide climates, J. Geophys. Res., 111, D05303, doi:10.1029/2005JD006459, 2006 b.

Mahowald, N., Rasch, P., Eaton, B., Whittlestone, S., and Prinn, R.: Transport of 222radon to the remote troposphere using the Model of Atmospheric Transport and Chemistry and assimilated winds from ECMWF and the National Center for Environmental Prediction/NCAR, J. Geophys. Res., 102, 139-151, 1997.

Meehl, G. A., Arblaster, J. M., and Collins, W. D.: Effects of black carbon aerosols on the Indian monsoon, J. Climate, 21, 28692882, 2008.

Patterson, E. M.: Optical properties of the crustal aerosol: Relation to chemical and physical characteristics, J. Geophys. Res., 86, 3236-3246, 1981.

Prospero, J. M. and Lamb, P. J.: African droughts and dust transport to the Caribbean: Climate change implications, Science, 302, 1024-1027, 2003.

Ramanathan, V., Chung, C., Kim, D., Bettge, T., Buja, L., Kiehl,
J. T., Washington, W. M., Fu, Q., Sikka, D. R., and Wild, M.: Atmospheric brown clouds: Impact on South Asian climate and hydrologic cycle, Proc. Natl. Acad. Sci. USA, 102, 5326-5333, 2005.

Ramanathan, V., Ramana, M. V., Roberts, G., Kim, D., Corrigan, C., Chung, C., and Winker, D.: Warming trends in Asia amplified by brown cloud solar absorption, Nature, 448, 575-579, 2007.

Rasch, P. J., Collins, W., and Eaton, B. E.: Understanding the Indian Ocean Experiment (INDOEX) aerosol distributions with an aerosol assimilation, J. Geophys. Res., 106, 7337-7355, 2001.

Reid, E., Reid, J., Meier, M. M., Dunlap, M. R., Cliff, S. S., Broumas, A., Perry, K., and Maring, H.: Characterization of African dust transported to Puerto Rico by individual particle and size segregated bulk analysis, J. Geophys. Res., 108, 8591, doi:10.1029/2002JD002935, 2003.

Remer, L. A., Kaufman,Y. J., Mattoo, S., Martins, J. V., Ichoku, C., Levy, R. C., Kleidman, R. G., Tanré, D., Chu, D. A., Li, R. R., Eck, T. F., Vermote, E., and Holben, B. N.: The MODIS Aerosol Algorithm, Products and Validation, J. Atmos. Sci., 62, 947-973, 2005.

Roberts, D. L. and Jones, A.: Climate sensitivity to black carbon aerosol from fossil fuel combustion, J. Geophys. Res., 109, D16202, doi:10.1029/2004JD004676, 2004.

Seinfeld, J. H. and Pandis, S. N.: Atmospheric Chemistry and Physics, From Air Pollution to Climate Change, J. Wiley \& Sons, New York, 1998.

Sinyuk, A., Torres, O., and Dubovik, O.: Combined use of satellite and surface observations to infer the imaginary part of refractive index of Saharan dust, Geophys. Res. Lett., 30, 1081, doi:10.1029/2002GL016189, 2003.

Sokolik, I. N., Andronova, A., and Johnson, T. C.: Complex refractive index of atmospheric dust aerosols. Atmos. Environ., 27A, 2495-2502, 1993.

Tegen, I., Hollrig, P., Chin, M., Fung, I., Jacob, D., and Penner, J.: Contribution of different aerosol species to the global aerosol extinction optical thickness: Estimates from model results, J. Geophys. Res., 102, 23895-23915, 1997.

Volz, F. E.: Infrared optical constants of ammonium sulfate, Sahara dust, volcanic pumice, and flyash, Appl. Opt.,12, 564-568, 1973.

Wang, C.: Impact of direct radiative forcing of black carbon aerosols on tropical convective precipitation, Geophys. Res. Lett., 34, L05709, doi:10.1029/2006GL028416, 2007.

Wang, C.: A modeling study on the climate impacts of black carbon aerosols, J. Geophys. Res., 109, D03106, doi:10.1029/2003JD004084, 2004.

Yoshioka, M., Mahowald, N., Conley, A. J., Collins, W. D., Fillmore, D. W., Zender, C. S., and Coleman, D. B.: Impact of desert dust radiative forcing on Sahel precipitation: Relative importance of dust compared to sea surface temperature variations, vegetation changes, and greenhouse gas warming, J. Climate, 20, 1445-1467, 2007

Zender, C., Bian, H., and Newman, D.: Mineral Dust Entrainment and Deposition (DEAD) model: Description and 1990s dust climatology, J. Geophys. Res., 108, 4416, doi:10.1029/2002JD002775, 2003.

Zender, C., Miller, R. L., and Tegen, I.: Quantifying mineral dust mass budgets: Terminology, constraints, and current estimates, EOS, 85, p. 509, 2004. 